\title{
A Comparative Study of Effect of Yoga on Symptoms and Drug Use in Bronchial Asthma
}

\author{
Sanjeev Satpathy ${ }^{1}$, Aiswarya $\mathrm{Kar}^{2}$, Kanhu Charana Purohit ${ }^{3}$, Rajesh Manik $^{4}$ \\ ${ }^{I}$ (Department Of Physiology, S.C.B Medical College, Odisha, India) \\ ${ }_{2}^{2}$ (Department Of Microbiology, S.C.B Medical College, Odisha, India) \\ ${ }^{3}$ (Department Of Physiology, V.S.S Medical College, Odisha, India) \\ ${ }^{4}$ (Yoga Trainer, Department of Ayush, AIIMS, Odisha, India)
}

\begin{abstract}
Out of many types of chronic diseases in the world, bronchial asthma is one of the most common, affecting young and old. Though no absolute cure has been discovered till date but a number of pharmaceutical interventions have been used to control it. Yogic exercises have be used to control asthma since long. The present study was an attempt to include yogic exercises into treatment modalities of asthmatic patients. 71 patients of bronchial asthma taken and randomised into 2 groups, Yoga Group And Control Group. Yoga Group Contained 37 Subjects Who Performed Yoga Along With Drug Intake And Control Group contained 34 subjects who underwent only therapeutic manoeuvre. The Asthma Symptom Score, Acute Exacerbation, Grade of Dyspnoea and Drug use were compared in both groups at baseline and at the end of the study after 4 months. The parameters were compared using various statistical analyses. After 4 months, YOGA GROUP subject showed a significant reduction in symptoms and reduction in drug use in comparison to Control Group. Thus we conclude that the Yoga breathing exercises used along with standard drug significantly reduces the symptoms and drug use in patients with bronchial asthma.
\end{abstract}

Keywords: Bronchial Asthma, Yoga, Acute exacerbation, Dyspnoea grade.

\section{Introduction}

Asthma is a syndrome. It is an episodic disease with acute exacerbations, interspersed with symptomfree periods[1]. Typically most attacks are short lived and patients seem to recover completely after an attack. Airway remodelling is related to the severity of the disease and may result in relatively irreversible narrowing of airways[2].

Pharmaceutical interventions are used in management like $\beta 2$ agonist, Corticosteroids while ignoring the Complementary and Alternative therapies. Yoga is one important of them which include number of postures, exercises and breathing techniques that has much curative effect on number of diseases including asthma. The aim of this study was to show that daily use of Yogic breathing exercises for some time can reduce both the symptoms of bronchial asthma and drug intake by the asthmatic patients. The objective of the study was to show that the asthmatics can have a better life to live with minimum side effects of drugs like bronchodilators and corticosteroids as well as facing less burden of cost of those life saving drugs that has to be taken on regular basis.

\section{Methods}

The study was a Randomised Controlled Trial with two different groups, consisting of adult patients with persistent, chronic asthma who have met the inclusion and exclusion criteria for the same. Initially the patients were stabilized on drugs till no further symptomatic improvement occurred. The study subjects were allocated to two groups; the Yoga Group that included those who practiced Yogic exercises along with drugs and the Control Group who received only drugs.

Inclusion criteria were i) Cases of Bronchial asthma confirmed by the Physician/Chest Physician as mentioned in diagnostic criteria and ii) With symptoms of asthma persisting for at least 6 months despite optimum therapy. Exclusion criteria were I) History of smoking within the last 1 year, II) Acute infection or infections within the past 6 weeks and III) Patients with serious systemic illness - Hepatic, Renal, Cardiac or CNS diseases. IV)Patients with cardiovascular diseases including hypertension.

71 subjects with chronic bronchial asthma attending the OPD of Pulmonary Medicine, VSS MC, were taken. They were allotted into two groups: CONTROL GROUP and YOGA GROUP, with 34 and 37 subjects respectively. All were males with no significant difference in mean age and BMI. Initially they were stabilized on drugs (Inhalational corticosteroids and Bronchodilators) till no further symptomatic improvement occur. The CONTROL GROUP continued the medicine and the YOGA GROUP were taught to perform five Yogic exercises daily, along with the same medication. The Yogic exercises included are Tadashana, Tiryaka Tadasana, Simhagarjanashana, Kastatakshyasana and Bhastrika Pranayama. The exercises were followed by 
relaxation or Shavasana. The Yoga was performed early in the morning with empty bowel and bladder. Initially breathing exercises were performed 10 times and then extended to 15-20 times after 2 weeks. Simhagarjanasana was started with 3-4 times at first and then extended after 2 weeks as per comfort. All subjects were instructed and performed the Yogic exercises under the guidance of Yoga instructor, Rajesh Manik. The criteria taken under consideration were Acute Exacerbation of asthma, Dyspnoea (studied by Dyspnoea Grading System), Asthma Symptom Score, use of Bronchodilators and Inhalational Corticosteroids.

The significance was found out by using McNemar's test and Wilcoxon Signed Rank test. Statistical analysis was done by using SPSS 16.0 software. $\mathrm{p}<0.05$ was taken as significance.

\section{Results}

The findings of the two groups at baseline and after 4 months of study have been shown in the table. Table 1: Shows the baseline demographical characteristics of the study subject in the two groups. No significant difference was seen between the age, height, weight and body mass index (BMI) between the subjects of the two groups. $p$ is calculated using Independent ' $t$ ' test.

\begin{tabular}{|c|c|c|c|}
\hline & Yoga Group & Control Group & p value \\
\hline Age $(\mathrm{Yr})^{*}$ & $25.27 \pm 2.28$ & $24.98 \pm 2.92$ & 0.216 \\
\hline Height $(\mathrm{cm})^{*}$ & $161.14 \pm 8.03$ & $162.24 \pm 8.23$ & 0.570 \\
\hline Weight $(\mathrm{kg})^{*}$ & $64 \pm 6.97$ & $66 \pm 6.76$ & 0.434 \\
\hline BMI $\left(\mathrm{Kg} / \mathrm{m}^{2}\right)^{*}$ & $25.14 \pm 3.33$ & $25.33 \pm 3.67$ & 0.819 \\
\hline
\end{tabular}

*Data is expressed as Mean \pm SD

Table 2: Shows number of subjects who had acute exacerbation before and after 4 months of intervention in each of the group $\mathrm{p}$ is calculated using McNemar's test.

\begin{tabular}{|c|c|c|c|c|}
\hline \multirow[b]{2}{*}{ Group } & \multirow[b]{2}{*}{ Timeline } & \multicolumn{2}{|c|}{ Acute exacerbations } & \multirow[b]{2}{*}{$\mathrm{p}$ value } \\
\hline & & Yes & No & \\
\hline \multirow{2}{*}{$\begin{array}{l}\text { Yoga Group } \\
(n=37)\end{array}$} & At Baseline & 24 & 13 & \multirow[b]{2}{*}{$<0.001$} \\
\hline & During 4 months of intervention & 8 & 29 & \\
\hline \multirow{2}{*}{$\begin{array}{l}\text { Control Group } \\
(n=34)\end{array}$} & At Baseline & 18 & 16 & \multirow[b]{2}{*}{0.065} \\
\hline & During 4 months of intervention & 11 & 23 & \\
\hline
\end{tabular}

Table 3: Shows the number of subject in the different Dyspnoea Grade[3] in both the groups at baseline and after 4 months of intervention. $\mathrm{p}$ is calculated using Wilcoxon Signed Rank Test.

\begin{tabular}{|c|c|c|c|c|c|c|}
\hline \multirow{2}{*}{ Group } & \multirow{2}{*}{ Timeline } & \multicolumn{4}{|c|}{ No. Of subjects with Dyspnoea grade of } & \multirow[b]{2}{*}{$P$ value } \\
\hline & & 1 & 2 & 3 & 4 & \\
\hline \multirow{2}{*}{$\begin{array}{c}\text { YogaGroup } \\
(\mathrm{n}=37)\end{array}$} & At baseline & 4 & 19 & 5 & 9 & \multirow{2}{*}{$<0.001$} \\
\hline & After 4 months & 23 & 13 & 1 & 0 & \\
\hline \multirow{2}{*}{$\begin{array}{l}\text { Control } \\
\text { Group } \\
(n=34)\end{array}$} & At baseline & 7 & 22 & 4 & 1 & \multirow{2}{*}{0.527} \\
\hline & After 4 months & 9 & 20 & 5 & 0 & \\
\hline
\end{tabular}

Garde 1: Not troubled by breathlessness except on strenuous exercise

Grade 2: Short of breath when hurrying or walking up a slight hill

Grade 3: Walks slower than contemporaries on level ground because of breathlessness, or have to stop for breath when walking at own pace

Grade 4: Stops for breath after walking about 100m or after a few minutes on level ground

table 4: Shows the proportion of subjects in each group for Asthma Symptom Score (ASS)[4]. p is calculated by using Wilcoxon Signed Rank Test.

\begin{tabular}{|c|c|c|c|c|c|c|}
\hline \multirow{2}{*}{ Group } & \multirow{2}{*}{ Timeline } & \multicolumn{3}{|c|}{ No. Of subjects with Asthma symptom score } & \multirow{2}{*}{ P value } \\
\cline { 2 - 6 } & & 0 & 1 & 2 & 3 & \\
\hline \multirow{2}{*}{$\begin{array}{c}\text { Yoga Group } \\
\text { (n=37) }\end{array}$} & At baseline & 0 & 14 & 21 & 2 & \multirow{2}{*}{$<0.001$} \\
\hline \multirow{2}{*}{$\begin{array}{c}\text { Control } \\
\text { Group } \\
(\mathrm{n}=34)\end{array}$} & Atter 4 months & 3 & 27 & 7 & 0 & \multirow{2}{*}{0.033} \\
\cline { 2 - 6 } & After 4 months & 0 & 15 & 18 & 1 & \\
\hline
\end{tabular}

Score 0: no symptoms, unrestricted usual daily activities.

Score 1: symptoms occurred, but with little or no discomfort, unrestricted usual daily activities.

Score 2: symptoms occurred were sometimes annoying or affecting usual daily activities. 
Score 3: symptoms severe, very little improvement after use of medication. Not able to perform usual daily activities.

Table 5: Shows number of patients with change in bronchodilator use in each group before and after intervention. $\mathrm{p}$ was calculated using McNemar's test.

\begin{tabular}{|c|c|c|c|c|}
\hline \multirow[t]{2}{*}{ Group } & \multirow[t]{2}{*}{ Timeline } & \multicolumn{2}{|c|}{$\begin{array}{c}\text { No. Of subjects on } \\
\text { bronchodilators }\end{array}$} & \multirow{2}{*}{$\mathrm{p}$ value } \\
\hline & & Yes & No & \\
\hline \multirow{2}{*}{$\begin{array}{l}\text { Yoga Group } \\
\quad(\mathrm{n}=37)\end{array}$} & $\begin{array}{l}\text { At baseline } \\
\text { (number) }\end{array}$ & 37 & 0 & \multirow{2}{*}{0.016} \\
\hline & After 4 months $\quad$ (number) & 30 & 7 & \\
\hline \multirow{2}{*}{$\begin{array}{l}\text { Control Group } \\
(\mathrm{n}=34)\end{array}$} & $\begin{array}{l}\text { At baseline } \\
\text { (number) }\end{array}$ & 34 & 0 & \multirow[t]{2}{*}{ No change } \\
\hline & After 4 months (number) & 34 & 0 & \\
\hline
\end{tabular}

Table 6: Shows number of patients with change in inhalational corticosteroid (ICS) use in each group before and after intervention. $\mathrm{p}$ was calculated using McNemar's test.

\begin{tabular}{|c|c|c|c|c|}
\hline \multirow{2}{*}{ Group } & Timeline & No. Of subjects on ICS & \multirow{2}{*}{ p value } \\
\cline { 2 - 4 } $\begin{array}{c}\text { Yoga Group } \\
(\mathrm{n}=37)\end{array}$ & $\begin{array}{c}\text { At baseline } \\
\text { (number) }\end{array}$ & 33 & No & \multirow{2}{*}{$<0.001$} \\
\cline { 2 - 4 } & After 4 months (number) & 9 & 28 & \multirow{2}{*}{1.0} \\
\hline \multirow{2}{*}{$\begin{array}{c}\text { Control Group } \\
(\mathrm{n}=34)\end{array}$} & $\begin{array}{c}\text { At baseline } \\
\text { (number) }\end{array}$ & 20 & 14 & \\
\cline { 2 - 4 } & After 4 months (number) & 21 & 13 & \\
\hline
\end{tabular}

\section{Discussion}

It has been seen that drug therapy even for prolonged period fails to control bronchial asthma. Many of the complementary and alternate medicine (CAM) are used to control asthma[5]. Yoga is one important branch of CAM. Pranayama and Ashana bring about a correct balance between the sympathetic and parasympathetic nervous system[6,14]. Though Yoga bring about a parasympathetic dominance, Pranayam like Bhastrika has sympathetic stimulatory effect[7,8]. The sympathetic effect causes airway smooth muscle relaxation. Regular practice of Yoga cleanses the airway, removes the mucus plugs and keep the bronchial tree open. These all have a significant effect on pulmonary function, asthma exacerbation, Asthma Symptom Score, Dyspnoea grade and drug dosage. Yoga also reduces psychological over activity and emotional instability[15].

Before the study the subjects of both study groups were matched for age, sex and BMI. All the subjects were under routine treatment and the frequency of Dyspnoea Grade, Acute Exacerbation, Asthma Symptom Score recorded at baseline by a set of questionnaires. After 4 months of study, it is seen that there was a decrease in Dyspnoea Grade in majority of patients. Most of subjects, who were in Dyspnoea Grade 2, entered Grade 1 after intervention. Also the Asthma Symptom Score showed an increase in number patients in Score 0 and 1 who were earlier in Score 2 and 3. Significant improvement was seen in both the groups. This matched with the work of Tandon MK[9], Jain SC and Talukdar B[10].

This study also showed that Pranayama and Ashanas also decreased acute exacerbation in subjects after the study. 16 subjects of Yoga Group showed reduction of acute exacerbation where as only 5 from the Control Group showed the same. The change was seen from the end of first month itself. This work too matched with the studies of Nagarathna etal[11] and Nagendra and Seetalaxmi[12].

Yogic practice tends to massage various part of spine and thoracic cage and condition the lungs, help strengthen the immune system function[13]. Deep, regulated, relaxed breathing helps to soothen the lining of the bronchial tree and helps in preventing irritation from external allergen. This helps in reducing the dose of drugs, i.e. the bronchodilators and ICS decrease by $18 \%$ and $72 \%$ respectively in Yoga Group where as in Control Group there is no decrease in bronchodilator intake and 5\% decrease in ICS use in patients. This matched with the work of Vedantan et al [16] and Vempati R[17].

\section{Conclusion}

The study clearly showed that four months of Yoga produced improvement in various symptoms of bronchial asthma and reduced the frequency of drugs use in asthmatics. Thus, it is strongly recommended that these breathing exercises of Yoga be used as an adjunctive therapy in the treatment for amelioration of chronic bronchial asthma and improve the life style and productivity of patients suffering from chronic bronchial asthma with proper guidance from yoga experts and clinicians. 


\section{References}

[1] James A. Airway remodeling in asthma. Curr Opin Pulm Med 2005; 11(1):1-6.

[2] Vignola AM, Mirabella F, Costanzo G, Di Giorgi R, Gjomarkaj M, et al. Airway remodeling in asthma. Chest 2003 ; 12 (3 Suppl):417S-22S.

[3] Darbee, Joan C, Ohatake, Patricia J. Outcome measures in Cardiopulmonaryphysical therapy:Medical Research Council (MRC) Dyspnoea Scale. Cardiopulmonary Physiotherapy Journal, 24(6) 2009.

[4] Terry S, LeGrand and David C Shelledy, University of Texas Health Science Centre, 2002 Open Forum Abstracts, Respiratory Care, The Science Journal of American Association For Respiratory Care.

[5] Naturopathic medicine, c Michael Alan Morton Ph.D, Mary Morton; excerpted from "Five steps to selecting the best alternative Medicine, New world Library; 1997.

[6] Cohn L, Elias JA, Chupp GL. Asthma: mechanisms of disease persistence and progression. Annu Rev Immunol 2004; $22: 789-815$.

[7] Bousquet J, Jeffery PK, Busse WW, Johnson M, Vignola AM.Asthma, from bronchoconstriction to airways inflammation and remodelling. Am J Respir Crit Care Med 2000;161(5):1720 45.93.

[8] James A. Airway remodeling in asthma. Curr Opin Pulm Med 2005; 11(1):1-6.

[9] Tandon MK, Adjunct treatment with yoga in chronic severe airway obstruction, Thorax 1978, Aug; 33(4):514-7.

[10] Jain SC, Talukdar B. Evaluation of yoga therapy programme for patients of bronchial asthma. Singapore medical journal, 1993 Aug; 34(4); 306-8.

[11] Nagarathna R, Nagendra HR. Yoga for Bronchial asthma: A controlled study. British Medical Journal (Clin Res Ed) 1985;291:1077-1079.

[12] Nagrathna R, H. R. Nagendra, and R. Seethalakshmi. Yoga chair breathing for acute episodes of bronchial asthma. Lung India, 1991, 9(4):141-144.

[13] Madanmohan, L Jatiya, K Udupa \& AB Bhavanani. Effect of yoga training on handgrip, respiratory pressures and pulmonary function. Indian Journal of Physiology Pharmacology, 2003; 47(4): 387-392.

[14] Angela Pirisi. MODIFYING YOUR YOGA PRACTICE WITH CALMING POSES CAN HELP YOU BREATHE EASIER. Yoga Journal. www.yogajournal.com/health/885.

[15] Kaptchuk R Jr. The web that has no weaver: Understanding Chinese medicine. 2nd edn. 2000.

[16] Vedanthan M.D., and N. V. Raghuram. Yoga Breathing Techniques (YBTs) in exercise induced asthma: A pilot study. International Journal of Yoga Therapy, 2003, no. 13, 45-49.

[17] Vempati R, Bijlani RL, Deepak KK. The efficacy of a comprehensive lifestyle modification programme based on yoga in the management of bronchial asthma: a randomized controlled trial. BMC Pulm Med. 2009 Jul 30; 9:37. 